\title{
Práticas educativas e estresse parental de pais de crianças pequenas com desenvolvimento típico e atípico
}

\section{Parental stress and educational practices of parents of young children with typical and atypical development}

\author{
Maria de Fátima Minetto ${ }^{1}$ \\ Maria Aparecida Crepaldi ${ }^{2}$ \\ Marc Bigras ${ }^{3}$ \\ Laura Ceretta Moreira ${ }^{4}$
}

\begin{abstract}
RESUMO
A educação dos filhos é sem dúvida um dos maiores desafios que os pais podem enfrentar. Educar é uma tarefa trabalhosa e pode se agravar com a chegada de um filho com deficiência intelectual. Nesse momento, é natural que todas as expectativas dos pais no que se refere à educação que almejavam dar ao filho sejam questionadas. O objetivo deste estudo é evidenciar o nível de estresse parental e as práticas educativas utilizadas por pais de crianças entre zero e seis anos de idade, tanto com desenvolvimento típico quanto com desenvolvimento atípico (deficiência intelectual e síndrome de Down). O método incluiu análises descritivas e inferenciais, com a participação de 61 pais, divididos em três grupos, cujos resultados permitem deduzir que há diferenças na escolha de práticas educativas entre
\end{abstract}

${ }^{1}$ Doutora em Psicologia pela Universidade Federal de Santa Catarina. Professora do Setor de Educação da Universidade Federal do Paraná, Brasil. E-mail: fa.minetto@gmail.com.

${ }^{2}$ Doutora em Saúde Mental pela Universidade de Campinas. Professora Associada do Departamento de Psicologia da Universidade Federal de Santa Catarina, Brasil. E-mail: maria. crepaldi@gmail.com.

${ }^{3}$ Doutor em Ciências Humanas Aplicadas pela Universidade de Montreal. Professor do Departamento de Educação Especializada da Universidade de Sherbrooke, Canadá. E-mail: bigras. marc@uqam.ca.

${ }^{4}$ Doutora em Educação pela Universidade de São Paulo. Professora do Setor de Educação da Universidade Federal do Paraná, Brasil. E-mail: laura.moreira@uol.com.br. 
os diferentes grupos de pais e que pais de filhos com deficiência intelectual são mais estressados que pais de crianças típicas e com síndrome de Down. A partir da pesquisa realizada, pode-se concluir que pais de filhos com desenvolvimento atípico precisam de redes de apoio eficientes que orientem suas práticas educativas. Sugere-se investir em novas pesquisas e na organização de programas estruturados para trabalhar com pais e filhos, a fim de minimizar o nível de estresse parental e favorecer práticas educativas eficientes.

Palavras-chave: práticas educativas parentais; estresse parental; desenvolvimento típico; desenvolvimento atípico; deficiencia intelectual.

\begin{abstract}
By assuming the parental role, parents face the challenge of educating. One of the adversities which can affect the family system is the birth of a child with intellectual disabilities. When it happens, it is natural for the family to question the education plan. Therefore, the objective of this research was to identify the educational practices used by parents of 3 to 6 year old children with typical and atypical development (intellectual disabilities and Down's syndrome) and the parental stress level. The method includes descriptive and inferential analysis. 61 parents participated in this research, whose results confirmed the hypothesis that different parental practices are chosen by different groups of parents, and that parents of children with intellectual disabilities are more stressed than the other parents. The hypothesis that the age of the children influences the parental practices was contradicted. This research concluded that parents of children with intellectual disabilities need a support network to guide their educational practices. New researches and programs to deal with these families should be done in order to minimize the stress level and support efficient educational practices.
\end{abstract}

Keywords: parental practices; parental stress; parental beliefs; family behavior; intellectual disability.

\title{
Introdução
}

Gerar uma criança é uma experiência marcante, que envolve sentimentos intensos e, muitas vezes, conflituosos, como alegria/felicidade, angústia/medo, entre outros. Passado o momento do nascimento, os pais percebem que o trabalho 
apenas começou, pois somado à tarefa de cuidar do desenvolvimento do filho, vivem a experiência de educá-lo num contexto social instável e, assim, na sua maioria, sentem-se despreparados no enfrentamento de tal tarefa. Este conjunto de situações costuma gerar estresse e dificulta que os pais possam exercer a paternidade da forma como desejariam.

Este desafio para algumas famílias torna-se maior quando descobrem que um de seus filhos é diferente e tem alguma anormalidade, como a deficiência intelectual ${ }^{5}$, o que pode gerar mais insegurança e dúvidas na tarefa de educar. Nesse momento, é natural que todas as programações dos pais no que se refere à educação que dariam ao filho sejam questionadas. Muitos autores explicam que o nascimento de um bebê com alguma anormalidade pode chocar os pais, frustrar seus sonhos ou desencadear reações e sentimentos que interferem na interação com o filho (OLIVEIRA, 2001; KLAUS; KENNELL; KLAUS, 2000). Neste sentido, é esperado que os pais possam manifestar sentimentos de angústia, desespero, medo e até rejeição nos primeiros momentos, como parte do processo da gradativa aceitação do bebê com deficiência.

Klaus, Kennell e Klaus (2000) salientam que, além de seu próprio turbilhão emocional, os pais que têm filhos com alguma deficiência precisam lidar com as expectativas daqueles que estão à sua volta, além de problemas de saúde que a criança possa apresentar, gerando uma carga alta de estresse. Para Buscaglia (1997), Klaus, Kennell e Klaus (2000), Prado (2005), Flamenghi e Messa (2007), dentre outros, é fundamental um trabalho intensivo de apoio e orientação às famílias com filhos especiais. Os autores evidenciam que o envolvimento da família desde cedo terá efeito positivo na relação de cuidado e no investimento oferecido no desenvolvimento da criança.

Darling e Steinberg (1993), Maturana (1993), Bronfenbrenner (1996), Szymanski (2004), Dessen e Costa Jr. (2005), dentre outros, salientam que o desenvolvimento da criança depende da qualidade das interações que se estabelecem na família. A partir dos primeiros cuidados dispensados ao bebê é que se estabelecem as relações de socialização. Os cuidados parentais dão início à práticas educativas que transmitem hábitos, valores, crenças, conhecimentos, enfim, subsídios para um convívio social. As práticas educativas parentais podem ser entendidas como conjuntos de comportamentos singulares manifestados pelos pais no processo de educação ou socialização dos filhos (DARLING; STEINBERG, 1993). Para Maturana (1993), a função parental exercida pelos

${ }^{5} \mathrm{O}$ termo "deficiência intelectual" é definido por limitações significativas tanto do funcionamento intelectual quanto no comportamento adaptativo do indivíduo. Atualmente a Association on Intellectual and Developmental Disabilities - AAIDD (2010) recomenda a utilização do termo "Deficiência Intelectual" em substituição ao termo "Deficiência Mental". 
pais e pelas mães sofre influência da história e da cultura do ecossistema. Para o autor, a paternidade e a maternidade são relações de cuidado e são afetadas pelo contexto sócio-histórico. O contexto, segundo Bronfenbrenner (1996), numa visão ecológica, é composto pelas propriedades da pessoa e do meio ambiente e os processos que ocorrem dentro dele podem ser considerados interdependentes e analisados em termos de sistemas.

Estudos como os de Maccoby e Martin (1983) e Steinberg (2001), dentre outros, consideram que o conjunto de práticas educativas utilizadas pelos pais caracteriza o estilo parental. Os autores partem de dimensões relativamente amplas de práticas parentais para então definir estilos parentais, dependendo do padrão do comportamento dos pais. Os estilos parentais, portanto, podem ser entendidos como o clima emocional dentro do qual práticas parentais específicas são implementadas (DARLING; STEINBERG, 1993).

Entendendo a família como promotora de desenvolvimento, pesquisas como as de Salvador e Weber (2005) e Marin e Piccinini (2007), preocupam-se em conhecer as práticas educativas utilizadas pelos pais em diferentes contextos. Os estudos na área reconhecem interdependência de fatores ligados à forma como as práticas educativas são exercidas, destacando condições externas e internas da família que podem trazer efeitos cumulativos ao longo do ciclo vital para todos os membros. Szymanski (2004) destaca as condições da dinâmica intrafamiliar (relação afetiva entre os membros da família) e extrafamiliar (pobreza, privações socioculturais, entre outros) como geradoras de sofrimento psicológico para pais e para filhos, afetando a escolha de práticas educativas e, consequentemente, a caracterização do estilo parental.

Macarini, Martins, Minetto e Vieira (2010) realizaram um levantamento bibliográfico que revela que são poucos os estudos a respeito de práticas educativas de pais com filhos com necessidades especiais nos bancos de dados de pesquisas nacionais (Index Psi, PEPsic e Scielo Brasil). Conforme os autores, com relação à deficiência intelectual, estes são mais restritos ainda.

A partir do exposto, a presente pesquisa se propôs a analisar as práticas educativas parentais de pais com filhos com desenvolvimento típico ${ }^{6}$ e atípico ${ }^{7}$. Também procurou verificar as influências do índice de estresse parental sobre as práticas educativas parentais em ambos os grupos.

${ }^{6}$ Considerou-se nesta pesquisa o termo "desenvolvimento típico" para crianças que têm o seu desenvolvimento geral conforme o padrão de referência, segundo a Organização Pan-Americana de Saúde (2005), dentro do esperado para sua idade cronológica, incluindo relacionamento, comportamento e aprendizagem escolar.

${ }^{7}$ Considerou-se nesta pesquisa o termo "desenvolvimento atípico" para crianças cujo desenvolvimento se afasta da média geral da população, do característico, apresentando atraso no que 
Trata-se de uma pesquisa de cunho explicativo e comparativo que teve como objetivo identificar o nível de estresse parental e as práticas educativas parentais utilizadas por pais de filhos com desenvolvimento típico e atípico.

\section{Método}

\section{Participantes}

Participaram da pesquisa 61 mães e/ou pais que possuíam filhos na faixa etária entre 03 e 06 anos, distribuídos em três grupos:

- 23 pais (14 mães e 9 pais) de filhos com desenvolvimento típico;

- 21 pais (11 mães e 10 pais) de filhos com deficiência intelectual (com deficiência intelectual sem características físicas sindrômicas aparentes);

- 17 pais (9 mães e 8 pais) de filhos com diagnóstico de síndrome de Down (com deficiência intelectual com características físicas sindrômicas aparentes, fenótipo).

Para cada criança, participou somente um dos familiares responsáveis (o pai ou a mãe).

Os pais tinham mais de 18 anos, o que foi estabelecido em virtude de ser a idade mínima a partir da qual o indivíduo é considerado legalmente responsável por suas ações, devido à necessidade de assinatura do Termo de Consentimento Livre e Esclarecido. Tratou-se de uma amostra de conveniência, de diferentes níveis socioeconômicos, que foi selecionada em escolas de ensino comum e especial em uma cidade do Sul do Brasil, onde os dados foram coletados.

Os pais de filhos com desenvolvimento típico foram agrupados em dois grupos, uma vez que crianças com síndrome de Down têm geralmente prognóstico e deteç̧ão precoce mais eficaz e maior acesso a grupos de apoio, evidenciados por associações e centros de atendimento específicos para esta síndrome.

\section{Procedimentos}

Os instrumentos utilizados para a esta pesquisa foram:

se espera para sua idade cronológica, incluindo relacionamento, comportamento e aprendizagem escolar, segundo a Organização Pan-Americana de Saúde (2005) e a Association on Intellectual and Developmental Disabilities - AAIDD (2010). Para esta pesquisa, quando é utilizado esse termo, referimo-nos a dois grupos: crianças com deficiência intelectual e crianças com síndrome de Down. 
Questionário sociodemográfico - Esse instrumento foi elaborado pelos professores autores deste artigo e inclui dados variados como idade, escolaridade, profissão, dentre outros que caracterizam a população participante desta pesquisa. Índice de Estresse Parental - PSI - Para avaliar o índice de estresse dos pais, utilizou-se o instrumento Índice de Estresse Parental - PSI (ABIDIN, 1995), na versão reduzida validada por Santos (1997), para a população de Portugal. O PSI destina-se a medir o estresse percebido pelos pais, e engloba três subescalas e o instrumento respostas defensivas:

- Subescala Função paterna - avalia percepções sobre os sentimentos vivenciados pelo genitor em seu papel de pai/mãe.

- Subescala Relacionamento pai/filho - avalia as percepções que os genitores têm de seus filhos que são ou não compatíveis com as suas expectativas, bem como as percepções de suas interações com a criança que não reforçam o seu papel de pai/mãe.

- Subescala Características do filho - focaliza algumas características comportamentais básicas de crianças que as tornam fáceis ou difíceis de manejar.

- Respostas defensivas - O instrumento avalia ainda o nível de respostas defensivas que o pai utilizou tentando se defender de perguntas que possam expô-lo a julgamento.

Para a correção do Índice do Estresse Parental - PSI, primeiramente as respostas são somadas por grupos das subáreas analisadas e, em seguida, os valores são colocados em uma tabela que permite a obtenção de índices que descrevem cada dimensão. O estresse total de um pai/mãe reflete as tensões que ocorrem nas áreas de angústia pessoal, tensões decorrentes da interação dos pais com o filho e as tensões que surgem nas características comportamentais da criança. Inventário de Práticas Parentais - CRPR - Trata-se de um instrumento amplamente utilizado em pesquisa que busca caracterizar práticas educativas. $\mathrm{O}$ CRPR - Child Rearing Practices Report (Relatório de Práticas de Educação Infantil) - foi desenvolvido por Block (citado em Dekovic, Janssens e Gerris, 1991). O inventário utilizado nesta pesquisa é uma adaptação holandesa feita por Dekovic, Janssens e Gerris (1991), os quais mostraram que o CRPR pode ser usado como um questionário com escala Likert, sem impedir a confiabilidade ou trazer prejuízos para a análise. São consideradas no Inventário de Práticas Parentais - CRPR - (DEKOVIC, 1989) as seguintes categorias de análise como representativas de:

Características que permeiam práticas educativas com Perfil Autoritário:

- Controle autoritário - refere-se a comandos diretos, imposições físicas, repreensões e proibições. 
- Supervisão da criança - refere-se à supervisão constante, em que os pais acompanham o que a criança faz.

- Indução e controle da ansiedade - referem-se a ameaças verbais ou não verbais sobre a consequência de seus atos.

Características que permeiam práticas educativas com Perfil Autoritativo:

- Orientação consistente - refere-se a orientações, sugestões e incentivo positivo.

- Estimulação e encorajamento à autonomia - referem-se ao estímulo e à tomada de decisões e conhecer a consequência de seus atos.

- Liberdade e expressão de afeto - implica permitir que pais e criança falem de seus sentimentos, além da expressão de afeto verbal e por meio de contato físico.

Para Dekovic (1989) e Dekovic, |Janssens e Gerris (1991), o instrumento CRPR obtém sucesso ao discriminar as práticas educativas parentais tanto de crianças sociáveis e de fácil relacionamento com os colegas quanto das negligenciadas. A correção do instrumento CRPR consiste na soma dos itens relacionados de cada categoria e na relação entre eles.

Os dados nesta pesquisa foram tratados por meio de análises descritivas (frequência, médias, desvio padrão), bem como por meio de análises inferenciais (testes paramétricos) (DANCEY; REIDY, 2006). As respostas dos instrumentos aplicados foram codificadas com o auxílio do programa estatístico SPSS-15.0 for Windows (Statistical Package for the Social Sciences).

\section{Resultados}

Os resultados foram contabilizados a partir do total de 61 participantes, sendo a análise feita por grupo de pais.

Com relação aos dados sociodemográficos, o grupo de pais de crianças com desenvolvimento típico resultou num total de 23 participantes. As mães apresentaram uma idade média de 31,61 anos (D.P. =7,01) e os pais, uma idade média de 33,74 anos (D.P. $=7,06$ ). Os filhos apresentaram uma idade média de 4,52 anos (D.P. $=1,12)$, sendo 11 meninos $(47,8 \%)$ e 12 meninas $(52,2 \%)$. O número de crianças dessas famílias foi de 1,52 (D.P. $=1,16)$ e todas elas frequentavam a escola regular. A escolaridade materna ficou concentrada no Ensino Superior Completo $(\mathrm{n}=5)$, seguido por Ensino Médio Completo $(\mathrm{n}=7)$, 
Ensino Fundamental Completo $(\mathrm{n}=1)$ e Ensino Fundamental Incompleto ( $\mathrm{n}$ =1). Com relação à escolaridade paterna, a concentração também ficou com o Ensino Superior Completo $(\mathrm{n}=3$ ), seguido pelo Ensino Médio Completo ( $\mathrm{n}$ $=4)$, Ensino Fundamental Incompleto $(\mathrm{n}=2)$. A situação conjugal dos casais que possuem filhos com desenvolvimento típico foi, em sua maioria, de casados $(69,6 \%)$, com quatro casais separados $(17,4 \%)$, dois com o pai recasado $(8,7 \%)$ e um com a mãe recasada $(4,3 \%)$.

O grupo de pais de filhos com deficiência intelectual foi composto de 21 participantes. As mães desse grupo tinham uma idade média de 34,05 anos (D.P. $=8,17$ ) e os pais, uma idade média de 36,33 anos (D.P. $=8,61$ ). As crianças apresentaram uma idade média de 5,19 anos (D.P. $=1,12$ ), sendo 15 meninos $(71,4 \%)$ e seis meninas $(28,6 \%)$. O número de filhos dessas famílias foi de 1,81 (D.P. $=1,29)$. Desse grupo, 19 crianças frequentavam Escola Especial e duas a Escola Regular. A escolaridade materna ficou concentrada no Ensino Médio Completo $(n=4)$, seguido por Ensino Fundamental Incompleto $(n=3)$, Ensino Superior Completo $(\mathrm{n}=3)$ e Ensino Fundamental Completo $(\mathrm{n}=1)$. Nos pais, a concentração também ficou no Ensino Médio Completo $(n=4)$, seguido pelo Ensino Fundamental Incompleto $(\mathrm{n}=3)$, Ensino Superior Completo $(\mathrm{n}=2)$, Ensino Fundamental Completo $(\mathrm{n}=1)$. Com relação à situação conjugal dos casais com filhos com deficiência intelectual, os dados revelam maior concentração em casados $(85,7 \%)$, com dois pais recasados $(9,5 \%)$ e uma mãe solteira $(4,8 \%)$.

Por fim, o grupo de pais com filhos com Síndrome de Down totalizou 17 participantes. A média de idade das crianças foi de 4,59 anos (D.P. = 1,18), das mães foi 40,29 anos (D.P. $=6,38$ ) e dos pais foi de 42,53 anos (D.P. $=7,98$ ). O número de filhos dessas famílias foi de 2,00 (D.P. $=1,23)$ e todas as crianças desse grupo frequentavam a escola especial. A escolaridade materna ficou bem distribuída e, dentre as mães, se identificaram o Ensino Médio Completo ( $\mathrm{n}=$ 3), o Ensino Superior Completo $(\mathrm{n}=2)$, o Ensino Fundamental Completo $(\mathrm{n}=$ 2) e o Ensino Fundamental Incompleto $(n=2)$. Os pais apresentaram o Ensino Médio Completo $(\mathrm{n}=2)$, o Ensino Fundamental Incompleto $(\mathrm{n}=3)$, o Ensino Fundamental Completo $(\mathrm{n}=1)$ e alguns não responderam $(\mathrm{n}=2)$. A situação conjugal dos casais do grupo de crianças com Síndrome de Down foi, em sua maioria, de casados $(76,5 \%)$, com três casais separados $(17,6 \%)$ e uma mãe solteira $(5,9 \%)$.

Na sequência, foram analisados dois instrumentos, o de Práticas Parentais e o de Estresse Parental. Iniciando com a medida de Práticas Parentais, apresentam-se na Tabela 1 os resultados de todas as dimensões em cada um dos grupos. 
TABELA 1 - MÉDIA DO INSTRUMENTO PRÁTICAS PARENTAIS EM CADA UM DOS GRUPOS DE ANÁLISE

\begin{tabular}{|c|c|c|c|c|c|c|c|c|}
\hline \multirow[b]{2}{*}{ Grupos } & \multicolumn{8}{|c|}{ Dimensões } \\
\hline & Autoridade & Supervisão & $\begin{array}{l}\text { Ind. } \\
\text { Ansiedade }\end{array}$ & $\begin{array}{l}\text { Total } \\
\text { Autoritário }\end{array}$ & Reflexão & Autonomia & Ex. Afeto & $\begin{array}{l}\text { Total } \\
\text { Autoritativo }\end{array}$ \\
\hline \multicolumn{9}{|c|}{ Desenvolvimento Típico } \\
\hline Média (D.P.) & $165,35(13,27)$ & $59,78(6,72)$ & $15,22(1,83)$ & $23,70(3,14)$ & $98,70(10,19)$ & $25,83(2,74)$ & $45,39(4,10)$ & $37,57(3,84)$ \\
\hline Mín./Máx. & $130 / 192$ & $44 / 75$ & $12 / 18$ & $18 / 30$ & $77 / 123$ & $20 / 30$ & $35 / 54$ & $28 / 42$ \\
\hline \multicolumn{9}{|c|}{ Deficiência Intelectual } \\
\hline Média (D.P.) & $154,62(20,78)$ & $58,14(9,47)$ & $14,19(2,89)$ & $22,14(6,54)$ & $94,57(15,79)$ & $\begin{array}{l}22,57 \\
(6,15)\end{array}$ & $40,62(6,93)$ & $35,43(3,87)$ \\
\hline Mín./Máx. & $199 / 188$ & $37 / 76$ & $8 / 18$ & $6 / 30$ & $71 / 120$ & $9 / 30$ & $26 / 53$ & $30 / 42$ \\
\hline \multicolumn{9}{|c|}{ Síndrome de Down } \\
\hline Média (D.P.) & $158,24(15,81)$ & $57,18(8,20)$ & $14,82(1,98)$ & $22,18(3,73)$ & $94,18(11,32)$ & $23,88(3,53)$ & $43,59(4,30)$ & $36,06(4,12)$ \\
\hline Mín./Máx. & $135 / 188$ & $38 / 73$ & $11 / 18$ & $14 / 27$ & $71 / 112$ & $17 / 29$ & $36 / 53$ & $29 / 42$ \\
\hline
\end{tabular}

FONTE: Os autores (2011)

A partir dessas médias, foi realizado o Teste de Análise de Variância (Anova), que compara as médias de cada uma dessas dimensões em cada grupo, buscando as diferenças estatisticamente significativas. AAnova indicou diferença estatisticamente significativa na dimensão Externalização do Afeto $(\mathrm{F}(60)=$ $4,51 ; \mathrm{p}<0,05)$ e na comparação par a par apontou que a diferença está entre o grupo de Desenvolvimento Típico e Deficiência Intelectual $(\mathrm{D}=0,86, \mathrm{p}<0,05)$. Esse resultado indica que os pais de crianças com desenvolvimento típico externalizam mais o afeto que os pais das crianças com deficiência intelectual e essa diferença é estatisticamente significativa e de força alta.

Com relação às correlações realizadas entre as dimensões de Práticas Parentais e os dados sociodemográficos, encontrou-se a correlação positiva no grupo de Desenvolvimento Típico entre o número de filhos e a Externalização do afeto, apontando que, quanto mais filhos, mais os pais externalizam o afeto.

Nos resultados com relação ao instrumento Índice de Estresse Parental, foram analisadas as médias de todas as dimensões. Esses dados podem ser visualizados na Tabela 2.

Da mesma forma que no Inventário de Práticas Parentais, o Índice de Estresse Parental teve as médias das dimensões comparadas entre os grupos com a Anova. Os resultados apontam que existem diferenças entre os grupos em todas as dimensões do instrumento. Na dimensão Resposta Defensiva ( $\mathrm{F}(60)$ $=3,27 ; \mathrm{p}<0,05)$, a diferença na comparação par a par indicou diferença estatisticamente significativa entre os grupos desenvolvimento típico e Síndrome de Down, indicando que este último grupo apresenta mais essa dimensão (D $=0,84, \mathrm{p}<0,05)$. Na dimensão Mal-Estar Paterno $(\mathrm{F}(60)=4,35 ; \mathrm{p}<0,05)$, a 
TABELA 2 - MÉDIA DO INSTRUMENTO ESTRESSE PARENTAL EM CADA UM DOS GRUPOS DE ANÁLISE

\begin{tabular}{llllll}
\hline \multirow{2}{*}{ Grupos } & \multicolumn{5}{c}{ Dimensões } \\
\cline { 2 - 6 } & $\begin{array}{l}\text { Resposta } \\
\text { Defensiva }\end{array}$ & $\begin{array}{l}\text { Mal-Estar } \\
\text { Paterno }\end{array}$ & $\begin{array}{l}\text { Interação } \\
\text { Disfuncional }\end{array}$ & $\begin{array}{l}\text { Caract. da } \\
\text { Criança }\end{array}$ & Estresse Total \\
\hline $\begin{array}{l}\text { Desenvolvimento } \\
\text { Típico }\end{array}$ & & & & \\
Média (D.P.) & $16,09(4,39)$ & $25,61(7,44)$ & $24,26(4,51)$ & $28,43(5,70)$ & $78,30(14,78)$ \\
Mín./Máx. & $8 / 23$ & $15 / 42$ & $17 / 33$ & $20 / 45$ & $55 / 103$ \\
Deficiência & & & & & \\
Intelectual & & & & & \\
Média (D.P.) & $18,09(5,21)$ & $28,76(8,84)$ & $30,71(6,47)$ & $33,00(5,81)$ & $92,48(15,76)$ \\
Mín./Máx. & $9 / 27$ & $15 / 47$ & $20 / 51$ & $22 / 45$ & $61 / 128$ \\
Síndrome de Down & & & & & \\
Média (D.P.) & $20,00(4,85)$ & $33,59(9,27)$ & $29,18(6,44)$ & $30,00(6,85)$ & $92,71(18,05)$ \\
Mín./Máx. & $12 / 29$ & $17 / 47$ & $20 / 42$ & $19 / 42$ & $59 / 125$ \\
\hline
\end{tabular}

FONTE: Os autores (2011).

diferença foi também significativa entre esses dois grupos $(D=0,95, p<0,05)$, apontando que os pais com crianças com síndrome de Down apresentam mais essa dimensão que os pais das crianças com desenvolvimento típico.

$\mathrm{Na}$ dimensão Interação Disfuncional, também houve diferença estatisticamente significativa entre o grupo $(\mathrm{F}(60)=7,37 ; \mathrm{p}<0,01)$. Nesse caso, nas comparações par a par, o grupo de pais de crianças com desenvolvimento típico apresentou diferença estatisticamente forte tanto com o grupo de pais de crianças com deficiência intelectual $(\mathrm{D}=1,17 ; \mathrm{p}<0,01)$ quanto com o de crianças com síndrome de Down $(\mathrm{D}=0,90 ; \mathrm{p}<0,05)$. Esse resultado aponta que os pais de filhos com desenvolvimento típico apresentam menor Interação Disfuncional que os outros dois grupos de análise.

Com relação à dimensão Criança Difícil, foi também encontrada relação estatisticamente significativa entre os grupos $(\mathrm{F}(60)=3,16 ; \mathrm{p}<0,05)$. Nessa relação, a diferença no par a par foi entre o grupo de crianças com desenvolvimento típico e o com crianças com deficiência intelectual $(\mathrm{D}=0,79 ; \mathrm{p}<$ $0,05)$, apontando que os pais de crianças com deficiência intelectual indicam seus filhos como mais difíceis em comparação com os pais de crianças com desenvolvimento típico.

Por fim, a dimensão Estresse Total apontou também um diferença entre os grupos $(\mathrm{F}(60)=5,65 ; \mathrm{p}<0,01)$. Essa diferença, assim como na dimensão 
Interação Disfuncional, ocorreu com o grupo de desenvolvimento típico em comparação com os outros dois grupos, o de crianças com deficiência intelectual $(\mathrm{D}=0,93 ; \mathrm{p}<0,05)$ e com o com síndrome de Down $(\mathrm{D}=0,88 ; \mathrm{p}<0,05)$. Dessa forma, essa análise permite inferir que os pais de crianças com desenvolvimento típico apontam menos estresse que os pais dos outros dois grupos.

Foram realizadas também correlações desse instrumento com os dados sociodemográficos e os resultados não apontaram nenhuma relação significativa entre essas variáveis.

\section{Discussão}

A interpretação dos resultados desta pesquisa evidencia que há diferença na escolha de práticas educativas entre os três grupos de pais estudados. Os pais de crianças com desenvolvimento típico apresentaram diferenças significativas no fator externalização do afeto se comparados com os pais das crianças com deficiência intelectual. Também ao se comparar as dimensões de Práticas Parentais e os dados sociodemográficos, encontrou-se a correlação positiva no grupo de desenvolvimento típico entre o número de filhos e a Externalização do afeto, apontando que, quanto mais filhos, mais os pais externalizam o afeto. Ainda os dados permitem deduzir que pais de filhos com síndrome de Down e deficiência intelectual tendem a utilizar estratégias de maior controle autoritário, maior supervisão da criança e controle da ansiedade do filho, caracterizando um perfil parental mais autoritário. Os pais de filhos com desenvolvimento típico apresentaram características de práticas educativas com perfil parental mais autoritativo, com destaque às estratégias que envolvem liberdade e expressão de afeto e incentivo à autonomia.

Baumrind (1991), Maccoby e Martin (1983) e Darling e Steinberg (1993) afirmam que as práticas parentais são compostas por estratégias utilizadas pelos pais para educar seus filhos e o conjunto dessas estratégias possibilita caracterizar o seu perfil parental. O perfil de práticas educativas parentais que mais se aproxima do grupo de pais com filhos com deficiência intelectual é do grupo de pais com filhos com síndrome de Down. Por outro lado, o grupo de pais de filhos com deficiência intelectual se diferencia muito dos pais de filhos com desenvolvimento típico, principalmente pela assimetria nas dimensões autoridade, autonomia e expressão de afeto. Pais de filhos com a síndrome de Down mostraram práticas educativas com alguma semelhança àquelas dos pais de filhos com desenvolvimento típico, evidenciando maior controle do comportamento 
da criança (supervisão) e menos investimento na autonomia. Apesar de o foco das pesquisas nesta área ser distinto e ainda muito limitado, existem estudos que corroboram os dados encontrados nesta pesquisa, que falam de conflitos nos relacionamentos de pais e filhos, dificuldades para educar, diferenças entre cuidados parentais, como Alvarenga (2000); Pereira-Silva e Dessen (2004, 2006); e Fiamenghi (2007).

Os pais de filhos com deficiência intelectual apresentaram práticas educativas que mais se diferenciam dos outros grupos de pais, com característica mais autoritária, com tendência a pouca supervisão das ações do filho, imposição de limites sem reflexão, e pouca expressão de afeto. Apesar de os grupos de pais apresentarem diferenças nas práticas parentais entre si, há mais proximidade na seleção de estratégias educativas de pais que possuem filhos com desenvolvimento típico e síndrome de Down, com destaque para a supervisão da criança, atendendo suas necessidades.

Pode-se considerar que os pais de filhos com síndrome de Down vivem situação diferenciada, ou seja, têm precocemente uma previsão do prognóstico de desenvolvimento da criança, favorecendo o investimento tanto na autonomia quanto no comportamento adequado para que esta possa ter um convívio social melhor. A síndrome de Down é a síndrome cromossômica mais estudada (SCHWARTZMAN, 1999), o que resulta em conhecimentos que orientam e dão mais segurança nas decisões dos pais, principalmente com relação ao desenvolvimento da criança. É possível que recebam maior orientação e incentivo às práticas educativas que promovam autonomia e adequação de comportamento social a fim de que seus filhos possam conquistar um espaço na sociedade, como um emprego, por exemplo. Kobarg e Vieira (2008) asseguram que o contexto tem influência sobre as crenças parentais e isso afeta a relação entre pais e filhos, com reflexos em relação à proximidade e ao afeto entre eles. Essa afirmação ajuda na compreensão da escolha de práticas de pais com filhos com deficiência intelectual.

O pais de filhos com desenvolvimento típico mostraram menor índice geral de estresse, confirmando os estudos encontrados na literatura sobre o estresse desencadeado pela presença de um membro na família com alguma necessidade especial, seja ela uma doença crônica, emocional ou deficiência física, intelectual ou sensorial (PEREIRA-SILVA; DESSEN, 2004, 2006; CHERUBINI; BOSA; BANDEIRA, 2008; MIRANDA et al., 2009). Para esses autores, o nível de estresse desses pais de filhos com necessidades especiais é muito mais alto do que os demais, consolidando o que foi identificado nesta pesquisa.

Apontam-se também as considerações de Keller (2007), que vê a influência das configurações culturais específicas de cada contexto como fundamental para se compreender e estudar o comportamento parental. A história de cada 
família, de cada pai e mãe, é permeada por valores e crenças que são a base das relações que estes estabelecem. Asseverar que pais com filhos com desenvolvimento atípico (deficiência intelectual e síndrome de Down) podem ter mais dificuldades em organizar as suas práticas educativas, maior nível de estresse e maior possibilidade na disfuncionalidade familiar seria coerente, no entanto, não se pode generalizar esta afirmação.

\section{Conclusões}

Os resultados permitiram concluir que há diferenças entre as práticas educativas parentais utilizadas pelos três grupos de pais estudados. Os pais de filhos com síndrome de Down apresentaram resultados intermediários, com índices mais próximos das práticas de pais com filhos com desenvolvimento típico. O grupo de pais que mais se diferenciou nas práticas educativas foi o de pais com filhos com deficiência intelectual. Os pais de filhos com síndrome de Down e com deficiência intelectual apresentaram maior índice de estresse do que os pais de filhos com desenvolvimento típico.

Ressalta-se a importância de se investir em ações de orientação e apoio aos pais na tarefa de educar seus filhos. Os pais de filhos com desenvolvimento típico, apesar de apresentarem estratégias de práticas parentais autoritativas, também evidenciaram que, em alguns momentos, tendem ao controle autoritário, o que leva pensar que também precisam de orientação. Sugere-se que diferentes instâncias como governo, escolas e igrejas fomentem a organização de programas estruturados para trabalhar com pais e filhos, oferecendo orientações, informações e recursos especializados. Tais programas podem colaborar para minimizar o nível de estresse parental, favorecendo a elaboração de estratégias de enfrentamento de situações adversas das quais se possa lançar mão no exercício da função paterna, o que colaboraria para a vida social e educacional.

Os pais de filhos com desenvolvimento atípico (com deficiência intelectual e síndrome de Down) precisam de redes de apoio específicas e eficientes para que possam reduzir o seu nível de estresse e orientar suas práticas educativas. Neste sentido, é necessária a ampliação da rede institucional de apoio para potencialização da família que, embora seja de responsabilidade do Estado, pode ser também oferecida por associações e organizações não governamentais. Apesar do avanço promovido pelas pesquisas realizadas nessa área, ainda há necessidade de empreendimentos, tanto em novos estudos voltados à compreensão da tarefa de educar quanto em ações que orientem os pais em sua função paterna. 
Práticas educativas parentais adequadas resultam num melhor desenvolvimento da criança, refletindo em todos os contextos em que ela está inserida, incluindo seu desempenho escolar e relacionamento social.

\section{REFERÊNCIAS}

AAIDD - American Association on Intellectual and Developmental Disabilities, 2010. Disponível em: $<\mathrm{http}: / / w w w . a a i d d . o r g>$. Acesso em: 12/ 2010.

ABIDIN, R. R. Parenting stress index. Odessa, FL: Psychological Assessment Resources, 1995.

ALVARENGA, P. Práticas educativas maternas e problemas de comportamento na infância. Dissertação (Mestrado em Psicologia) - Programa de Pós-Graduação em Psicologia do Desenvolvimento, Universidade Federal do Rio Grande do Sul, Porto Alegre, 2000.

BAUMRIND, D. Effective parenting during the early transition. In: COWAN, P. A.; HETHERINGTON, M. (Ed.). New Jersey: Lawrence Erlbaum, 1991. p. 111-163.

BRONFENBRENNER, U. A. Ecologia do desenvolvimento humano. Porto Alegre: Artes Médicas, 1996.

BRONSTEIN, P. Differences in mothers' and fathers' behaviors toward children: A cross-cultural comparison. Developmental Psychology, v. 20, n. 6, p. 995-1003, 1984.

BUSCAGLIA, L. Os deficientes e seus pais: um desafio ao aconselhamento. Rio de Janeiro: Record, 1997.

CHERUBINI, Z. A.; BOSA, C. A.; BANDEIRA, D. Estresse e autoconceito em pais e mães de crianças com a síndrome do X-frágil. Psicologia Reflexão e Crítica, v. 31, n. 3, p.23, 2008.

DANCEY, C. P.; REIDY, J. Estatística sem Matemática para Psicologia: usando o SPSS para Windows. Porto Alegre: Artmed, 2006.

DARLING, N.; STEINBERG, L. Parenting style as a context: an integrative model. Psychological Bulletin, v. 113, p. 487-496, 1993.

DEKOVIC, M. Measuring dimensions and patterns of child rearing: Dutch Version of Block Child Rearing Practices Report (CRPR). Interne Publicatie E. P. Netherlands: Katholieke Universiteit Nijmegen, 1989.

; JANSSENS, J. M. A.; GERRIS, J. R. M. Factor structure and construct validity of the block child rearing practices report (CRPR). Psychological Assessment: A Journal of Consulting and Clinical Psychology, v. 3, n. 2, p. 182-187, 1991. 
DESSEN, M. A.; COSTA JR.; A. L. A ciência do desenvolvimento humano: tendências atuais e perspectivas futuras. Porto Alegre: Artmed, 2005.

; PEREIRA-SILVA, N. L. Deficiência mental e família: uma análise da produção científica. Cadernos de Psicologia e Educação Paideia, v. 10, p. 12-23, 2001.

FIAMENGHI, G. J.; MESSA. A. A. Pais filhos e deficiência: estudo sobre as relações familiares. Psicologia Ciência e Profissão, v. 27, n. 2, p. 236-245, 2007.

KELLER, H. Cultures of Infancy. Mahwah: Lawrence Erlbaum Associates, 2007.

KLAUS, M.; KENNELL, J.; KLAUS, P. Vinculo: construindo as bases para um apego seguro e para a independência. Porto Alegre: Artes Médicas, 2000.

KOBARG, A. P. R.; VIEIRA, M. L. Crenças e práticas de mães sobre o desenvolvimento infantil nos contextos rural e urbano. Psicologia Reflexão e Crítica, v. 21, n. 3, p. 401-408, 2008.

KOCHANSKA, G.; KUCZYNSKI, L.; RADKE-YARROW, M. Correspondence between mothers' self-reported and observed child-rearing practices. Child Development, v. 60, p. 56-63, 1989.

MACARINI, S. M.; MARTINS, G. D. F.; MINETTO, M. F.; VIEIRA, M. L. Práticas parentais: uma revisão da literatura brasileira. Arquivos Brasileiros de Psicologia, v. 62 , n. 1, p. $127,2010$.

MACCOBY, E.; MARTIN, J. Socialization in the context of the family: Parent-child interaction. In: HETHERINGTON, E. M.; MUSSEN, M. P. H. (Ed.). Handbook of child psychology: socialization, personality, and social development. v. 4. New York: Willey, 1983. p. 1-101.

MARIN, A. H.; PICCININI, C. A. Comportamentos e práticas educativas maternas em famílias de mães solteiras e famílias nucleares. Psicologia em Estudo, v. 12, n. 1, p. 13-22, jan. abr., 2007.

MATURANA, H. R. Amor y juego: fundamentos olvidados de lo humano desde el patriarcado a la democracia. Santiago: Instituto de Terapia Cognitiva, 1993.

MIRANDA, A.; GRAU, D.; ROSE, J.; MELIÁ, A. Understanding discipline in families of children with Attention-Deficit/Hyperactivity Disorder: a structural equation model. The Spanish Journal of Psychology, v. 12, n. 2, p. 496-505, 2009.

OLIVEIRA, L. O desejo parental diante do impacto do diagnóstico de síndrome de Down. Dissertação (Mestrado em Psicologia do Desenvolvimento) - Programa de Pós-Graduação em Psicologia do Desenvolvimento, Universidade Federal do Rio Grande do Sul, Porto Alegre, 2001.

ORGANIZAÇÃO PAN-AMERICANA DE SAÚDE. Manual de Vigilância do Desenvolvimento Infantil no contexto da AIDPI. Washington DC: OPAS, 2005. 
PEREIRA-SILVA, N. L.; DESSEN, M. O que significa ter uma criança deficiente mental na família? Educar em Revista, n. 23, p. 161-183, 2004.

. A. famílias de crianças com síndrome de Down: sentimentos, modos de vida e estresse parental. Interação em Psicologia, v. 10, n. 2, p. 183-194, jul. dez. 2006. PRADO, A. F. A. Família e deficiência. In: CEVERNY, C. M. O (Ed.). Família e... São Paulo: Casa do Psicólogo, 2005.

SALVADOR, A. P.; WEBER, L. N. D. Práticas educativas parentais: um estudo comparativo da interação familiar de dois adolescentes distintos. Interação em Psicologia, v. 9, n. 2, p. 341-353, 2005.

SANTOS, S. V. Versão portuguesa do Parenting Stress Index (PSI): Validação preliminar. In: GONÇALVES, M. Avaliação psicológica: formas e contextos. v. 5. Braga: Associação dos Psicólogos Portugueses, 1997. p. 139-149.

SCHWARTZMAN, J. S. Síndrome de Down. São Paulo: Mackenzie, 1999.

STENBERG, R. J. Psicologia cognitiva. Porto Alegre: Artes Médicas, 2000.

SZYMANSKI, H. Práticas educativas familiares: a família como foco de atenção psicoeducacional. Revista Estudos de Psicologia, v. 21, n. 2, p. 5-16, maio-ago. 2004.

Texto recebido em 24 de agosto de 2011.

Texto aprovado em 28 de outubro de 2011. 